
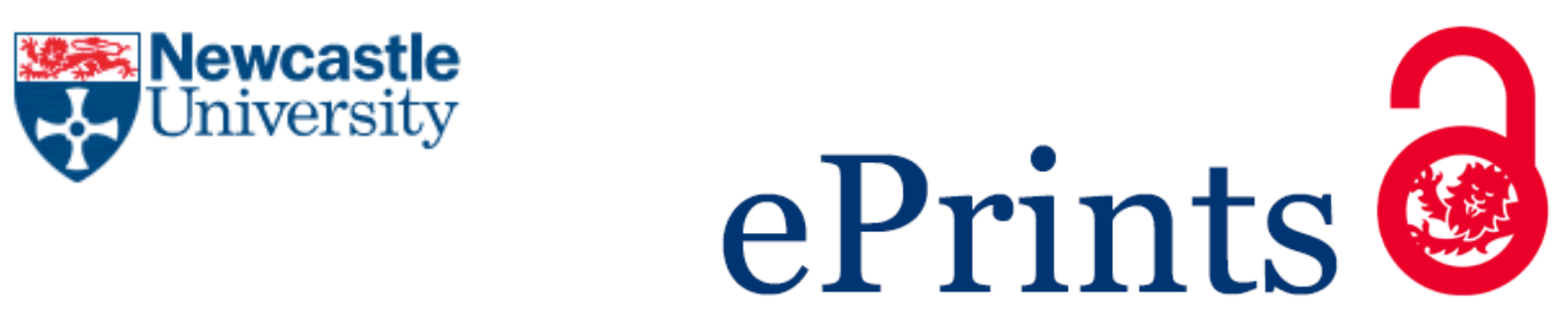

Hausberg JP, Valentino A, Sabini L.

Environmental Turbulence and Complexity and the Optimal Degree of Internal Open Innovation for MNCs.

International Journal of E-Services and Mobile Applications 2013, 5(4): 1.

Copyright:

Copyright (C 2013, IGI Global. Reproduced with the publisher's permission.

DOI link to article:

https://doi.org/10.4018/ijesma.2013100101

Date deposited:

$25 / 07 / 2017$ 


\section{INTERNATIONAL JouRNAL OF E-SERVIces AND MobILe Applications}

October-December 2013, Vol. 5, No. 4

Table of Contents

Special Issue on Seeking Higher Effectiveness in InNovation and KNOWLEDge Management

\section{Guest Editorial Preface}

iv Alberto Francesconi, Department of 'Economics and Management Sciences', University of Pavia, Pavia, Italy Concetta Metallo, Dipartimento di Studi Aziendali ed Economici, "Parthenope" University of Naples, Naples, Italy

\section{Research Articles}

1 Environmental Turbulence and Complexity and the Optimal Degree of Internal Open Innovation for MNCs

J. Piet Hausberg, Department of Business and Management, LUISS Guido Carli, Rome, Italy \& School of Business and Social Sciences, University of Hamburg, Hamburg, Germany

Alfredo Valentino, Department of Business and Management, LUISS Guido Carli, Rome, Italy

Luca Sabini, Department of Business and Management, LUISS Guido Carli, Rome, Italy

25 Online Communities and Open Innovation: The Solar System Metaphor

Alberto Francesconi, Department of 'Economics and Management Sciences', University of Pavia, Pavia, Italy Riccardo Bonazzi, Department of Information Systems, Faculty of Business and Economics (HEC), University of Lausanne, Lausanne, Switzerland

Claudia Dossena, Department of 'Economics and Management Sciences', University of Pavia, Pavia, Italy

40 Building a Knowledge Experience Base for Facilitating Innovation

Pasquale Ardimento, Dipartimento di Informatica, Università degli Studi di Bari Aldo Moro, Bari, Italy Vito Nicola Convertini, Dipartimento di Informatica, Università degli Studi di Bari Aldo Moro, Bari, Italy Giuseppe Visaggio, Dipartimento di Informatica, Università degli Studi di Bari Aldo Moro, Bari, Italy

\section{Book Review}

50 Knowledge and Technological Development Effects on Organizational and Social Structures Joan-Francesc Fondevila-Gascón, Department of Communication Sciences, Universitat Abat Oliba CEU, Barcelona, Spain \& Cable Studies Centre (CECABLE), Terrassa, Spain

Copyright

The International Journal of E-Services and Mobile Applications (IJESMA) (ISSN 1941-627X; eISSN 1941-6288), Copyright (C) 2013 IGI Global. All rights, including translation into other languages reserved by the publisher. No part of this journal may be reproduced or used in any form or by any means without witten permission from the publisher, except for noncommercial, educational use including classroom teaching purposes. Product or company names used in this journal are for identification purposes only. Inclusion of the names of the products or companies does not indicate a claim of ownership by IGI Global of the trademark or registered trademark. The views expressed in this journal are those of the authors but not neccessarily of IGI Global.

The International Journal of Computer-Assisted Language Learning and Teaching is currently listed or indexed in: Bacon's Media Directory; Cabell's Directories; DBLP; GetCited; Google Scholar; Google Scholar; INSPEC; JournalTOCs; Library \& Information Science Abstracts (LISA); MediaFinder; Norwegian Social Science Data Services (NSD); The Index of Information Systems Journals; The Standard Periodical Directory; Ulrich's Periodicals Directory 


\title{
Environmental Turbulence and Complexity and the Optimal Degree of Internal Open Innovation for MNCs
}

\author{
J. Piet Hausberg, Department of Business and Management, LUISS Guido Carli, Rome, Italy \\ \& School of Business and Social Sciences, University of Hamburg, Hamburg, Germany
}

Alfredo Valentino, Department of Business and Management, LUISS Guido Carli, Rome, Italy

Luca Sabini, Department of Business and Management, LUISS Guido Carli, Rome, Italy

\begin{abstract}
In today's knowledge economy, it is vital for Multi-National Corporations (MNCs) to leverage all their globally dispersed knowledge resources. Extant literature argues that MNCs can be viewed as knowledge sharing networks and that knowledge exchange within the group enhances performance. This exploration of new knowledge through search among peer subsidiaries of the parent MNC can be regarded as Internal Open Innovation (IOI). However, literature on Open Innovation is largely focused on the external boundary of the firm, so that little can be said on whether openness towards corporate group internal knowledge sources is either or both, beneficial and/or detrimental, and how this depends on the difference of national industries and on the correct communication of these before the final transfer of knowledge. The principal research question thus is: To what degree should MNC subsidiaries be open to their intra-MNC peers given a common, evolving technological environment but different local market contexts? In this paper, the authors contribute with new propositions regarding this issue developed based on results from an agent-based model that is analyzed through computer simulation. The authors explore the degree of openness of MNC subsidiaries together with their communication competence in different organizational structures and environments, based on previous developments in theory of knowledge transfer and complexity as well as international business.
\end{abstract}

Keywords: $\quad$ Agent-Based Model, Computer Simulation, Intra-firm Knowledge Integration, Internal Open Innovation (IOI), Multi-National Corporations (MNCs)

\section{INTRODUCTION}

The concept of knowledge transfer within the $\mathrm{MNC}$ and its impediments have received increasing attention in the international business literature since the seminal work of Dunning
(1981). In fact, the MNC can be considered as a "knowledge based entity", where different units seek to transmit, transfer, integrate and leverage knowledge across national boundaries (Foss \& Pedersen, 2004) and its raison-d'être has been claimed to lie exactly in its superior

DOI: $10.4018 /$ ijesma.2013100101 
capacity to transfer knowledge across national boundaries (Kogut \& Zander, 1993). It has been suggested that knowledge transfers within the MNC take place within the context of an interorganizational "network" of differentiated units (subsidiaries) (Bartlett \& Ghoshal, 1990; Gupta \& Govindarajan, 2000; Hendlund, 1986). MNC subsidiaries have been recognized not only as mere exploiters of knowledge that is centrally held by the MNC, but also as generators of knowledge in their own right (Za \& Spagnoletti, 2013) and a way to tap locally the internationally distributed knowledge (Kuemmerle, 1997). Increasingly, also the lateral knowledge exchange, i.e. that directly among the subsidiaries, is focus of studies of intra-MNC knowledge transfer (e.g. Gupta \& Govindarajan, 2000). This follows in analogy to the development of the concept of Open Innovation on the overall firm level (Chesbrough, 2003). Chesbrough - and large part of the literature following him - argues that knowledge has become too complex and the environment to turbulent as to continue to manage the innovation process in a closed, stand-alone manner.

We assume that also subsidiaries that aim at knowledge and innovation generation have to open their search process to the expertise of the very peer subsidiaries with which they compete on resources, charter amplification, and headquarters' attention. MNCs that incentivize or else foster the opening of the innovation process of their subsidiaries in this direction, i.e. towards their intra-MNC peers, can be thus said to apply "internal open innovation" (IOI). But necessarily the questions arise whether this IOI is always beneficial for the MNC and which factors could constitute important contingencies.

As far as regards innovation as an adaptive process, environmental uncertainty has been found to be a major contingency co-determining the efficacy of various approaches to innovation (Eisenhardt \& Tabrizi, 1995). Environmental uncertainty is usually regarded as determined mainly by the two factors "environmental complexity" and "environmental dynamism" (Duncan, 1972). The impact of environmental uncertainty on innovation is in large part the result of the potential for erosion or depreciation of the value of existing knowledge in that becomes outdated. In so far, environmental uncertainty, or concretely its dynamism and complexity, can be deemed to be major contingencies of the effectiveness of IOI as well.

On the one extreme, there are low complexity, low dynamic industries and on the other one, there are highly dynamic high-tech industries. In between there are industries that are very dynamic but not very complex, as for example a large part of the so-called "fast moving consumer goods", which exhibit a large amount of fast fading trends without being actually hightech products in most cases. Other industries present a considerable degree of complexity, but exhibit — at least periodically — little dynamism, as for example some electronics industries. However, while environmental uncertainty has been studied broadly with regard to its impact on both innovation and firm performance, it remains unclear how its two major constituencies - complexity and dynamism - do individually affect the appropriateness of intra-MNC IOI in terms of innovativeness, particularly considering that subsidiaries of an MNC might be exposed to different market contexts even if the technological environment with which they deal is the same. This casts doubt on a simple linear, positive relationship between knowledge integration and innovation performance.

This research gap is gaining relevance due to the fact that today's knowledge economies increasingly augment in both complexity and dynamism in a large variety of industries. This leads inevitably to the question of what is the optimal degree to which MNC subsidiaries should openly exchange knowledge with their intra-MNC peers given a common, evolving technological environment but different local market contexts.

We approach this research question by means of an agent-based computer simulation model. This model permits us to get a clear picture of the relations between IOI and the two environmental contingencies, complexity and dynamisms. We test furthermore whether our 
findings are altered by the degree to which the local country market actually is important to the MNCs, i.e. whether the MNC is innovating in an international industry - characterized by very different demands in different countries - or in a global industry - characterized by rather homogeneous demand worldwide. Finally, we check whether findings are robust for different degrees of interdependence between knowledge areas.

We find that environmental complexity substantially alters the effect of environmental dynamism on the generally positive effect of IOI. The simulations suggest furthermore that there are fundamental differences between international and global industries and that the impact of IOI on innovation performance is indeed not always linearly positive, but can also be n-shaped in several combinations of levels of environmental complexity and dynamism.

In the following section we discuss the theoretical background of the concepts on which we build our model that we describe in detail in the subsequent section. Following the model description we present the results that than are discussed in order to develop our propositions based thereupon. In the concluding section, our contributions are summarized and implications for future research and management practice are discussed.

\section{THEORETICAL BACKGROUND}

\subsection{Innovation in the MNC}

Innovation has been defined at all possible levels of analysis from the individual to transnational organizations (Scott \& Bruce, 1994; Wolfe, 1994). What is common to the vast majority of the relevant literature though is that innovation is understood not as a mere invention, but rather as the commercially successful application of an invention, be it in form of products, production processes, services, or organizational procedures, structures, governance mechanisms or else.
Firms are increasingly driven to internationalize both from the supply side as well as the demand side, in that pressure to internationalize their innovative activities comes from the fact that knowledge has to be sought globally in an increasing number of industries and pressure to internationalize sales activities comes from increasing competition maturing homemarkets and/or increasing growth opportunities in emerging market countries. However, the technology underlying inventions - be it products, processes, or services - might be universally the same, but the value that is attributed to them is defined by the market demand which can be rather heterogeneous across national markets. In fact, the principal difference between international industries visà-vis global industries is that the former exhibit considerable demand-side heterogeneity across country markets, whereas truly global industries do not (Ghoshal \& Nohria, 1993). Firms that compete worldwide in international industries respond to this circumstance by investing more in local subsidiaries in order to be closer to the market and adapt their overall knowledge base to the local requirements. Since the underlying technology might however still be globally the same, an essential part of knowledge can potentially be very valuable to peers.

In fact, in line with social capital theory, which holds that the ties held by members of a network permit them to exchange social resources and thus create value (Bourdieu, 1986), extant literature in international business claims that the MNC as a whole can be understood in terms of a network in which various organizational sub-units (the subsidiaries) can be more or less inclined to share knowledge among each other(Bartlett \& Ghoshal, 1990). The exchange of knowledge between organizational units has indeed become a main focus of the resource based view in form of the Knowledge Based View of the firm (Spender \& Grant, 1996; Grant, 1996). In fact, the higher ability of firms visà-vis markets to transfer knowledge is seen as one if not the raison-d'être of the MNC (Kogut \& Zander, 1993). 
According to early theories on how knowledge, or more generally firms' intangible assets, can influence the internationalization process, knowledge is spawned at the home base and subsequently diffused among the firm's international business units as new products or processes (Almeida \& Phene, 2004). On basis of a large number of case studies it was found that the organization of international innovation can exhibit further schemes. Bartlett and Ghoshal (1990), proposed four organizational approaches to international innovation: (1) the classical 'centre-for-global', (2) its extreme counterpart 'local-for-local', where internationally dispersed R\&D sites work on new products and processes for their respective location, (3) 'locally-leveraged', where local R\&Dresources are used to develop innovations for the global market, thus rather 'local-for-global', and (4) 'globally-linked', where resources and capabilities of internationally dispersed $R \& D$ sites are pooled to jointly innovate. Each organizational form has its specific advantages and disadvantages.

Therefore, it has been noted that both, the degree of innovation and internationalization, can differ sensibly between different corporate functions. It has been found, for example, that commonly the R\&D function is less internationalized than production and sales (e.g. Zedtwitz \& Gassmann, 2002). Moreover, also in divisionally structured MNCs the charters of the various subsidiaries might have clear foci on either competence exploration or competence exploitation. This has also been termed 'homebase augmenting' or 'home-base exploiting' (Kuemmerle, 1997) and is closely related to the resulting predominant innovation behavior of subsidiaries, which has been classified for example into local market, internal market, and global market initiatives (Birkinshaw \& Hood, 1998).

To be able to manage a portfolio of subsidiaries with different objectives means to have the opportunity to balance exploration and exploitation (March, 1991) at the international corporate group level. To achieve ambidexterity, i.e. equal ability to explore and exploit knowledge, by means of leveraging the hence globally dispersed knowledge of subsidiaries requires intra-organizational knowledge integration across national boundaries (e.g. Gupta \& Govindarajan, 2000).

In comparison to the literature on open innovation, which is characterized by very high degrees of collaboration and/or integration with firm-external environment in the innovation process, in this work we focus on the "internal" open innovation, in the sense that the openness of the subsidiaries refers to the degree to which subsidiaries seek knowledge from their peer subsidiaries within the MNC to which they belong in order to enhance their innovation performance. Therefore, we develop our model as considering the $\mathrm{MNC}$ as a network of knowledge based entities, where these different units seek the most appropriate knowledge across national boundaries (Foss \& Pedersen, 2004). MNCs are complex multi-dimensional entities, in which knowledge flows occur not only along multiple directions but also across multiple dimensions (Gupta \& Govindarajan, 2000).

\subsection{Internal Open Innovation}

Openness is generally understood as the willingness to share knowledge (Albino, Garavelli, \& Schiuma, 1998; Chesbrough, 2004; Hamel, 1991). Wathne, Roos, and Von Krogh (1996) argue that "openness can be understood in terms of overall perceived openness of dialogue, the degree to which the partner representatives work closely together on a common task, and the degree to which the partner representatives perceive that the others withhold their knowledge" (Wathne et al., 1996). Research in Open Innovation is increasingly considering different levels of openness. Gassmann \& Enkel (2004), underline the need to transform "a company's solid boundaries into a more semi-permeable membrane to enable innovation to move more easily between the external environment and the company's internal innovation process", thus underlining the bi-directionality of the concept. Furthermore, Chesbrough (2002, 2003), describes the need for a shift of organizational 
innovation strategy into a more flexible open innovation approach at different levels, thus eventually pointing also to the consideration of openness of subsidiaries.

In line with Jerez-Gómez, Céspedes-Lorente, and Valle-Cabrera (2005), who consider individual level openness, it can be argued that also MNCs have to commit to a culture of knowledge exchange - or even explicitly incentivizing it - in order to build a climate of openness and avoid the rejection of outside knowledge without consideration of its actual value, i.e. avoid forms of the not-inventedhere syndrome (Katz \& Allen, 1982). This can be achieved by countering the formation of "egocentric attitude", that is a potentially detrimental inclination of considering the value of the centrally developed knowledge, strategies or culture as better than that of the rest of the group (McGill, Slocum, \& Lei, 1992). A similar negative consequences of sticking too firmly to the once developed own knowledge is the possibility that this previously valuable knowledge changes its character from a core-competence to a core-rigidity due to environmental dynamism (Leonard-Barton, 1992).

We focus on the subsidiary level in the context of internal MNC-networks, arguing that differences across industries regarding the heterogeneity of their various national markets, i.e. the degree to which a certain industry is rather global or rather international, determines how the internal openness of subsidiaries in an MNC-network structure impacts innovation performance.

In particular, we define Internal Open Innovation (IOI) as the behavior of subsidiaries to actively search for innovation partners amongst their peer subsidiaries in other divisions and countries throughout the entire MNCs and providing the entire knowledge stock to their intra-MNC peers if asked for ${ }^{1}$. Since subsidiaries in MNCs compete with each other on resources, power, autonomy and/or headquarters' attention (Mudambi \& Navarra, 2004), reasons similar to those theorized for firms in general might thus drive them to apply innovation strategies that are rather closed with respect to the MNC or even prefer knowledge from their local environment over that from their MNC-internal peer subsidiaries as a particular variation of the classic not-invented-here syndrome (Katz \& Allen, 1982).

\subsection{Environmental Dynamism and Complexity}

Superior knowledge can constitute a resource advantage, which has been recognized long since in strategic management as a way to successfully cope with hypercompetition although this kind of advantage is also claimed to be not sustainable (D'Aveni, 1994). Therefore, this fundamental assumption of the RBV (Barney, 1991) might not apply to very dynamic and complex environments, while at the same time - seemingly paradoxically - it might account as the reason for the development of the KBV (Grant, 1996) since it is in this environments that cutting-edge knowledge can appropriate enormous value in the short period before it depreciates.

To some degree, complexity and dynamism are interwoven (Aldrich, 1979). Given that in complex environments the different dimensions depend in their effects on the states of a relatively high number of other dimensions - as might be expressed for example by interoperability also of e-governance systems (Charalabidis, Lampathaki, \& Askounis, 2010)—a particular degree of change in dimensions in complex environments will evoke higher performance landscape changes than the same degree of change causes ceteris paribus in less complex environments. This might also explain why they are often investigated together in form of environmental uncertainty. Eisenhardt and Tabrizi (1995) for example find a moderating effect of environmental uncertainty on the effectiveness of two opposed product innovation strategies. However, it is not further investigated how the two principal components of uncertainty, i.e. dynamism and complexity, interact to produce such an effect nor whether this effect holds true also for knowledge transfer across countries. Moreover, it has been contested re- 
cently that more knowledge transfer is always better, arguing that it varies across firms and their respective environmental contexts (Reus, Ranft, Lamont, \& Adams, 2009). Indeed, this intuition has been long since theorized in form of the "interpretive systems view" or sensemaking (Daft \& Weick, 1984). Consequently, Reus and colleagues theorize, that firms might well over- and under-invest into knowledge acquisition and transfer.

\subsection{Knowledge Integration in MNCs}

In international business literature, scholars have given substantial attention to the knowledge transfer process among different units (Bartlett \& Ghoshal, 1990; Gupta \& Govindarajan, 2000; Kogut \& Zander, 1992; Mudambi \& Navarra, 2004). Knowledge transfer can be understood as the "process through which one unit exerts influence on other units" (Argote \& Ingram, 2000). Szulanski (1996, 2000) argues that transfer of knowledge is best understood by identifying and defining its various subprocesses or stages. This process is divided in his framework into four parts: initiation, implementation, ramp-up, and integration. While acknowledging the merits of this framework, we apply a somewhat more basic one herein. In particular, we distinguish two steps, the source evaluation stage and the knowledge transfer stage. Both together taking place at the level of subsidiary lead to knowledge integration at the level of the MNC. In both stages knowledge is transferred, but different one.

In the evaluation phase, organizational units have to search among their contacts within (and as possible beyond) their ego-network those partners that are most probably able to contribute to the searcher's innovative activities. Therefore, the knowledge that has to be transferred is such that permits the searching subsidiary to evaluate whether the source's technological knowledge might be fruitfully applied in the own market context. Hence, market contexts have to be compared and to this end knowledge has to be transferred regarding each potential source's market context.

In the transfer stage, the four stages initiation, implementation, ramp-up, and integration can be collocated. This requires a good fit between the partners' relevant environments. In fact, Szulanski (1996) finds that the degree of performance in sharing the knowledge between two entities depends on how the distance between these two entities (communicative gap) is bridged.

According to the knowledge based view, several further very different reasons might inhibit successful knowledge exchange, such as geographical distance - particularly relevant in international settings - and stickiness - particularly relevant in knowledge intensive industries. These points have been raised in RBV literature (J. S. Brown \& Duguid, 1991), in knowledge transfer literature (Szulanski, 2000) and in MNC literature (Bartlett \& Ghoshal, 1990; Hansen, 1999; Kogut \& Zander, 1992, 1993). For example, the way in which knowledge is transferred most successfully might vary from case to case according to the repository in which the knowledge is embedded. Several classes have been theoretically distinguished in that knowledge can be embedded. Walsh and Ungson (1991), for example, distinguish organizational members, physical and functional design, routines, and culture, whereas Argote and Ingram (2000) categorize more generally members, tools, and tasks. However, it could be argued that the principal difference is the degree of tacitness across these categories. This might be justified by the fact that in all instances organizational members have to mediate the transfer of the knowledge, be it the skills that are embedded within themselves or the tools they use and the tasks they execute. In all instances someone has to be aware of or evaluate the performance characteristics of the knowledge however embedded.

Hence, in both stages of knowledge integration complexity might well influence the success of knowledge transfer efforts. However, we want to establish herein the utility of knowledge integration in relation to the 
environment independently from issues of the ability to transfer knowledge or absorptive capacity, because the question herein is not how absorptive capacity influences innovation performance, but whether it should be aimed at absorption in the first place ${ }^{2}$. To this end we have to abstract from these issues assuming perfect absorptive capacity in both stages of knowledge integration.

\section{METHODOLOGY}

In recent years, an increasing amount of studies could be witnessed that applied agent-based computer simulations in management research (e.g. Gavetti \& Levinthal, 2000; Levinthal, 1997; Marengo \& Dosi, 2005; Rivkin \& Siggelkow, 2003; Sakhartov \& Folta, 2012; Siggelkow \& Rivkin, 2005). Herein, we explore the issue using the classical NK model (Kauffman, 1993), which builds the backbone of this research stream. This model is useful to describe in a simple, intuitive way an environment composed of several interacting dimensions, where each dimension can be in one of several possible states. The parameter $N$ indicates the number of dimensions that impact on performance. The parameter $K$ indicates the 'degree' of interaction between these dimensions. Concretely, $K$ determines the number of other dimensions that impact its performance contribution. For each of the $N$ dimensions, it is randomly determined which exactly are these $K$ other dimensions that influence its performance contribution. Consequently, for each configuration of any single dimension and its respective $K$ dimensions that co-determine its impact, a performance contribution is randomly drawn from the uniform distribution $(0,1)$. Since all dimensions can take the two states 0 and 1 , for each single dimension $\mathrm{n}$ there are $2^{K+1}$ distinct potential performance contributions.

The great value of Kauffman's (1993) model lies in the possibility to easily tune both the overall size of the landscape and the number of its local "hills and valleys", that is its complexity, via changes to its two parameters $N$ and $K$. When the parameter $K$ is high, landscapes are called "rugged" (see Figure 1 for an example), which refers to their characteristic of exhibiting many local optima and "valleys of attraction" that lead to them as opposed to a little complex

Figure 1. Example of a rugged NK-fitness landscape (Source: Based on Gavetti \& D. A. Levinthal (2000:119-120))

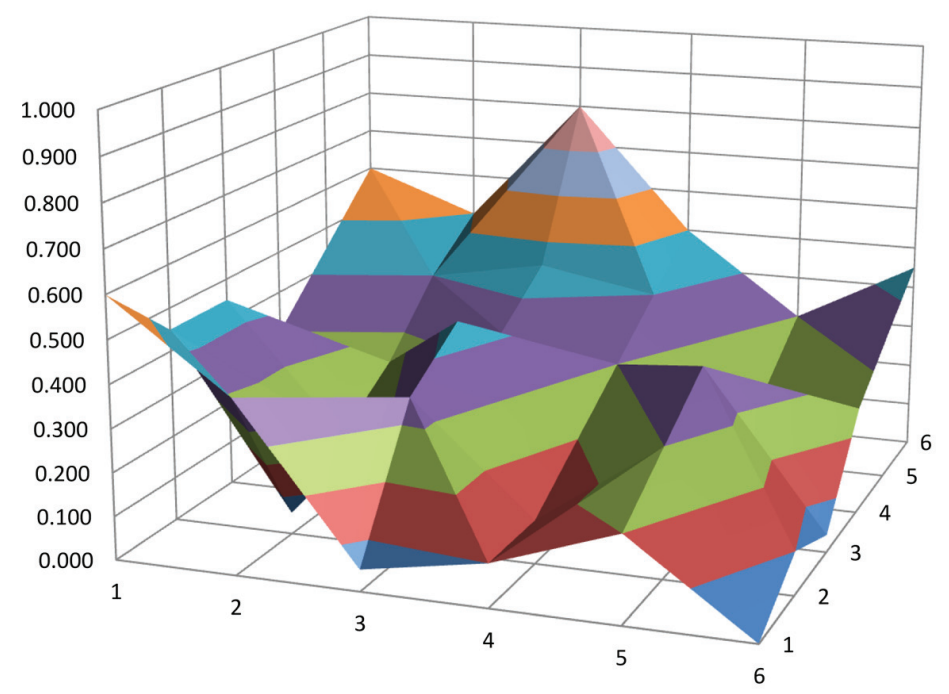


single-optimum landscape (see Figure 2 for an example). The term "valleys of attraction" already indicates that the performance of local searchers in this setting depends crucially on their point of departure. This is because the searching subjects are assumed to be boundedly rational, or more generally resource constrained, and therefore cannot explore all possible combinations and take an informed decision to move to the global optimum.

In our model, subsidiaries are likewise resource constraint in that they search the landscape according to a simple hill-climbing heuristic. That is, in each period, subsidiaries choose randomly one variable for which they analyze whether a change in its state would have a positive effect on performance or not. Thus we assume the subsidiaries are boundedly rational in terms of analyzing capacity and without memory, but they nonetheless possess perfect information on the underlying relations of the environment, i.e. their analysis is limited, but within these limits flawless.

\section{MODEL}

We base our model principally on the NK-model elaborated by Gavetti, Levinthal, \& Rivkin (2005) (henceforth GLR). GLR build a very effective model to analyze analogical reasoning. The GLR-model permits to analyze in a still relatively simple way relatedness of different optimization landscapes. We will build on this for the modeling of different country markets and hence the degree to which the industry exposes the MNC to different local conditions in the varying markets. This shall be the context in which we propose to explore the impact of varying degrees of openness of subsidiaries on organizational innovation performance.

Each single landscape draws from a contribution matrix that determines the interrelatedness of the various dimensions of the industry, just as in the classic NK-model. We focus our analysis on diversified MNCs, because most MNCs in fact operate on average in as many as five different sectors in terms of SIC codes (Habib \& Victor, 1991). Therefore, another element of the GLR-model is adapted accordingly. The degree of diversification is modeled as the degree to which different areas of competence or technological fields in which the MNC is active are coupled. Therefore, landscapes depend on $P$ high-level policy decisions (technological domains) and $D$ detailed decisions that have to be made within each policy decision, such that $P x D$ is the total number of decisions each firm makes. Each decision can take the values 0 or 1

Figure 2. Example of a single-optimum NK-fitness landscape (Source: Based on Gavetti \& D. A. Levinthal (2000:119-120))

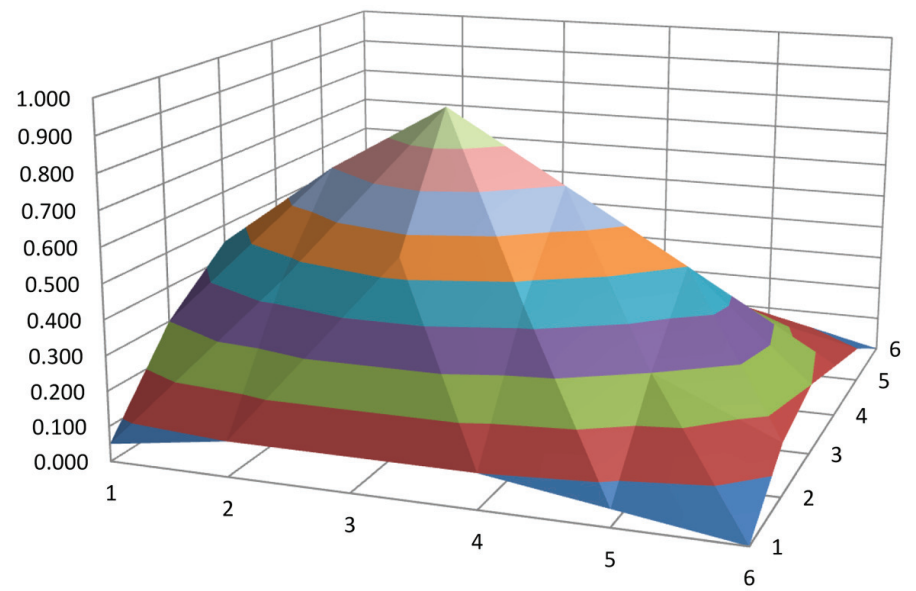

Copyright (C) 2013, IGI Global. Copying or distributing in print or electronic forms without written permission of IGI Global is prohibited. 
and a firm has thus $2^{P x D}$ possible overall decision combinations to choose from. Each high-level policy is simply equal to the state of the majority of the corresponding detailed decisions, i.e. if $\left\{\begin{array}{lll}1 & 0 & 0\end{array}\right\}$ than this policy would equal zero and for the configuration $\left\{\begin{array}{lll}1 & 0 & 1\end{array}\right\}$ it would equal 1 . The parameters $K_{w}$ and $K_{b}$ regulate how much the decisions within a high-level policy depend on each other and how much they depend on other high-level policies, respectively. Hence, while $K_{w}$ determines the number of other operative decisions on which a focal operative decision's performance contribution is based and thus can be compared to the parameter $K$ in the original NK-model as determining basic complexity, $K_{b}$ determines how much this focal decision depends on the state of policy decision different from the own one. Therefore, if $K_{b}$ is high, this can be interpreted as low, or closely related diversification, while if $K_{b}$ is low, this is comparable to a situation of unrelated diversification.

Moreover, supplementing the traditional NK-model, the GLR-model generates "families of landscapes". The performance contribution of each decision of the distinct country landscapes potentially depends on one or more of $X$ observable industry characteristics, which has been introduced in the GLR model. Altogether this constitutes for each country a distinct influence matrix. For each of the $X$ industry characteristics the parameter $X_{R E L}$ determines the probability that it influences each decision's performance contributions of each possible configuration of its influencing factors and its own state. Thus, while the factors $K_{w}$ and $K_{b}$ determine the degree of complexity as in the GLR-model, $X_{R E L}$ determines the degree of local dependence, that is whether the industry is rather international (high local dependence) or rather global (everywhere almost same conditions).

For a given set of the parameters $P, D, X$, $K_{w}, K_{b}$, and $X_{R E L}$ the computer hence initializes a new influence matrix for each simulation run (see all parameters in Table 1). Since the industry characteristics can take two states, 0 or 1 , there are $2^{X}$ different local industry landscapes possible. In the GLR-model the computer then generates one target landscape and $2^{X-1}$ source landscapes to draw analogy from. In our model,

\section{Table 1. Parameters of the modified GLR-model}

\begin{tabular}{|c|c|c|}
\hline \multirow{5}{*}{$\begin{array}{l}\text { Parameters } \\
\text { related to } \\
\text { the industry } \\
\text { characteristics }\end{array}$} & $P^{*}$ & $\begin{array}{l}\text { Number of policy decisions that the MNC faces on its industry's technological } \\
\text { landscape. Policy decisions are equal to the value that is most represented among } \\
\text { the operative decisions }\end{array}$ \\
\hline & $D^{*}$ & $\begin{array}{l}\text { Number of operative decisions that the MNC faces on its industry's technological } \\
\text { landscape. }\end{array}$ \\
\hline & $K_{w}$ & Number of dependencies between operative decisions within each policy area \\
\hline & $K_{b}^{*}$ & $\begin{array}{l}\text { Probability that the performance contribution of a focal detailed decision is } \\
\text { affected by the resolution of each }\end{array}$ \\
\hline & $E_{D Y N}$ & $\begin{array}{l}\text { Probability that the performance contribution for each operative decision for } \\
\text { each possible combination of influence factors changes. }\end{array}$ \\
\hline \multirow{2}{*}{$\begin{array}{l}\text { Parameters } \\
\text { related to } \\
\text { the MNC } \\
\text { characteristics }\end{array}$} & $X^{*}$ & $\begin{array}{l}\text { Number of market characteristics co-determining operative decisions' } \\
\text { performance contribution }\end{array}$ \\
\hline & $X_{R E L}$ & Probability that a focal market characteristic influences each operative decision. \\
\hline \multirow{2}{*}{$\begin{array}{l}\text { Parameters } \\
\text { related to MNC's } \\
\text { subsidiaries' } \\
\text { search behavior }\end{array}$} & IOI & $\begin{array}{l}\text { Probability that a subsidiary absorbs the knowledge of an intra-MNC peer once } \\
\text { identified as similar. }\end{array}$ \\
\hline & Strictness & $\begin{array}{l}\text { The percentage of market characteristics that have to be equal in a potential } \\
\text { source subsidiary to consider it sufficiently similar. }\end{array}$ \\
\hline
\end{tabular}

* Parameter as in the original GLR-model. Other parameters are additional or adapted.

(cf. Gavetti, Levinthal, \& Rivkin, 2005:698) 
however, out of these $2^{X}$, one country landscape is chosen randomly for each subsidiary. These country landscapes can be thus more or less similar to each other as concerns the state of the $X$ industry characteristics. This forces subsidiaries to get information on the local contexts of the peer subsidiaries from which they want to gather innovative knowledge before their engagement in knowledge transfer to accelerate innovation. Otherwise they would implement insights valid for a totally different context, but not in the own one, running the risk to considerably worsen performance.

A further difference is the introduction of dynamism as the rate of change in the industry characteristics, $E_{D Y N}$, which determines the dynamism of the environment. More precisely, the parameter $E_{D Y N}$ indicates the probability for every single detailed choice's performance contribution to change for each possible configuration of its own state and all relevant other factors.

Each subsidiary ${ }^{3}$ is initialized as an array of detailed decisions in its local context. Its individual payoff resulting from this configuration of decisions is determined by its individual landscape being a combination of the MNCs technological environment and the subsidiaries local market characteristics. Given the thus elaborated model, the payoffof any subsidiary $s$ can be written as a function of the configuration of the operative decisions and environmental characteristics:

$$
\begin{aligned}
& \pi_{s}\left(\begin{array}{l}
\left\{d_{1}, d_{2}, \ldots, d_{P_{x D}}\right\},\left[x_{1}, x_{2}, \ldots, x_{X}\right], \\
X_{R E L}, K_{w}, K_{b}
\end{array}\right) \\
& =\frac{1}{\operatorname{PxD}} \sum_{i=1}^{P_{x} D}\left(\pi_{i}\left(\begin{array}{c}
d_{i}, d_{j(i)}^{1} \ldots d_{j(i)}^{K_{w}}, p_{q(i)}^{1} \ldots \\
p_{q(i)}^{T_{i}\left(K_{b}\right)}, x_{r(i)}^{1} \ldots x_{r(i)}^{M_{i}\left(X_{R E L}\right)}
\end{array}\right)\right) \\
& i \notin j(i), i \notin q(i), i \cup j(i) \subseteq a(i)
\end{aligned}
$$

where:

$$
\begin{aligned}
& \pi_{i}(.) \text { is the performance contribution of a } \\
& \text { particular operative decision } \mathrm{i} \text {; }
\end{aligned}
$$

$j(i)$ is the set of indexes of other decisions that influence the decision with index $i$; $q(i)$ is the set of indexes of other policies that influence the decision with index $\mathrm{i}$;

$a(i)$ is the set of indexes of other decisions that relate to $\mathrm{p}_{\mathrm{i}}$;

$d_{j(i)}^{k}$ is the k-th element of the vector q of technological areas' policy decisions that influence $\pi_{\mathrm{i}}($.$) ;$

$\mathrm{p}_{\mathrm{q}(\mathrm{i})}^{\mathrm{t}}$ is the t-th element of the vector $\mathrm{q}$ of technological areas' policy decisions that influence $\pi_{i}($.$) ;$

$x_{r(i)}^{m}$ is the $m$-th element of the vector $r$ of market characteristics that influence $\grave{A}_{1}($.$) ;$ $T($.$) is the number of market characteristics$ that influence $\pi_{i}($.$) , which depends on the$ degree of relatedness of diversification, the probability $K_{b}$;

$\mathrm{M}($.$) is the number of market characteristics$ that influence $\mathrm{A}_{1}($.$) , which depends on the$ relevance of the local market environments, probability $X_{R E L}$;

The overall MNC performance is the average of the performance levels of its subsidiaries described in formula (1). Like this, performance will always on all levels result between 0 and 1 and be comparable. The performance of an $\mathrm{MNC}$ is thus given by the following formula(2):

$\pi_{M N C}=\frac{\sum \pi_{s}}{S}$

where $\mathrm{S}$ is $\mathrm{t}$ number of subsidiaries and $\mathrm{s}$ is a given subsidiary.

Our model constitutes a fundamental elaboration of the GLR-model in that in its original version, firms can choose only one time, that is at the beginning of the exploration of a new landscape, a certain starting point as an educated guess based on analogy drawn from 
more or less broad and deep experience of its managers, rather than simply start anywhere at random. In contrast to that, subsidiaries in our model constantly have the chance to jump out of valleys of attraction based on exchange of knowledge with peer subsidiaries of their MNC group the knowledge of whom likewise is not perfect but subject to optimizatioefforts.

Hence, there are two fundamental differences between our model and the original model. Firstly, the experience of the subsidiaries co-evolves throughout the model and the performance that any single one holds is not necessarily already a local let alone the global optimum of the particular local landscape from which knowledge is drawn. Secondly, this exchange of knowledge on what is a valuable, innovative combination of decisions is not exchanged once, but might be exchanged constantly. More precisely, internal open innovation(IOI) is modeled as the probability that a given subsidiary in a given period would seek superior knowledge among its peer subsidiaries. However, even if a subsidiary eventually engages in seeking superior knowledge in a certain period, this does not mean that knowledge transfer takes place. This is due to the division of the process into a pre-transfer phase and the actual transfer phase. In the former, the searching subsidiary compares its own local environment to that of its peers and consequently - amongst those that exhibit the same set of environmental conditions as the searching one itself-chooses the topperformer, in case there is any that performs at least as good as the searching subsidiary itself plus a risk margin of $20 \%$. In the transfer phase then, the states of all operative decisions of the thus found top-performer amongst the peers are copied. The reason why we do not want to leave out of the model a risk margin is that in cases where two subsidiaries perform equally well, no knowledge transfer should take place because it would represent an unnecessary cost plus the risk of integrating knowledge overestimated in its value, thus suffering a reduction of performance. The exact choice of the risk margin is obviously arbitrary. However, small scale sensitivity analysis did not indicate any substantial influence of the exact value of this parameter on the results.

We do specify the following additional assumptions that are fundamental for our research question. Firstly, subsidiaries can gather perfect information about the source's environmental state. Secondly, the searching subsidiary does not limit its transfer to one policy area, but gathers the knowledge on all decisions. Thirdly, the communication between the source and receiver subsidiaries is flawless. All three assumptions help to focus on the key argument and allow for a parsimonious model, but we might want to relax them in future elaborations of the model.

The parameters of the overall model are thus described by those that describe the industry, i.e. whether it is global or international, high-tech or low-tech, dynamic or static, and those that describe the MNC, i.e. how many subsidiaries in different country markets it counts and how open this are towards knowledge of their corporate group peers' knowledge. The overall process of knowledge integration within the MNC is illustrated in Figure 7 in the Appendix. The model was coded and run in NetLogo.

\section{RESULTS}

In order to analyze the influence of environmental turbulence and complexity, we simulate various scenarios. This allows us to analyze how sensitive the effects of Internal Open Innovation (IOI) of MNC subsidiaries in terms of overall $\mathrm{MNC}$ performance are to changes in these factors. The parameter values regarding the industry were set to 3 policy decisions with 4 decisions each and the country landscapes were modeled with 4 local market dimensions, which are the same values as chosen in the original GLR-model. For this analysis, the parameter $K_{b}$ was set to 0.2 , which aims at simulating diversified MNCs, i.e. such where the different policies or technological areas are only loosely coupled. We focus our analysis on diversified MNCs since these have been found to operate on average in five different 
sectors according to SIC classification (Chang \& Park, 2005; Habib \& Victor, 1991) and in recent years the phenomenon of diversified MNCs (DMNCs) has increased dramatically (Doukas \& Kan, 2006). Moreover, the need for access and sharing information and knowledge is higher in DMNCs, because one of their main goals is to exploit synergies among different internal units (Benito, Lunnan, \& Tomassen, 2010; Doz \& Prahalad, 1991; Goold, Pettifer, $\&$ D. Young, 2001).

The parameters for low, medium, and high IOI were set to $0,0.2$, and 0.5 , those for zero, low, medium, and high dynamism $\left(E_{D Y N}\right)$ to 0 , 1,5 , and 10 , while those for low and high complexity $\left(K_{w}\right)$ were set to 1 and 3 , respectively. The number of subsidiaries was set to 10 . In order to distinguish international industries, the parameter $X_{R E L}$ was set to 0.5 . Hence, the probability that any given decision's contribution is affected by the state of any given environ- mental factor $X$ is $50 \%$. For global industries this was set to $0.2^{4}$. In the two comparison scenarios "Medium IOI" and "High IOI" the percent change vis-à-vis the baseline scenario is reported, together with an indication of the one-tailed significance level. The static simulation runs tend to stabilize between the $40^{\text {th }}$ and $70^{\text {th }}$ period. Therefore, all scenarios have been run for slightly the double amount of periods, i.e. 150. An example of the development of running average overall $\mathrm{MNC}$ performance in a complex and dynamic environment is given in Figure 8 in the Appendix.

We present the results both in form of two distinct tables for international (Table 2 and global (Table 3) industries as well as in form of illustrations (Figures 3 through 6).

As previously highlighted, the crucial difference between international and global industries is the degree to which the local markets differ. The fact that in international

Table 2. Innovation performance across different scenarios in international industries

\begin{tabular}{|c|c|c|c|c|c|c|c|c|c|}
\hline \multirow{2}{*}{\multicolumn{2}{|c|}{$\begin{array}{c}\text { Observations: } 200 \\
\begin{array}{c}\text { Simulations Per } \\
\text { Scenario }\end{array} \\
\text { Complexity: }\end{array}$}} & \multicolumn{8}{|c|}{ Global Industries $\left(\mathrm{X}_{\mathrm{REL}}=0.5\right)$} \\
\hline & & \multicolumn{4}{|c|}{ Low complexity $\left(K_{w}=1\right)$} & \multicolumn{4}{|c|}{ High Complexity $\left(K_{w}=3\right)$} \\
\hline \multicolumn{2}{|c|}{$\begin{array}{r}\text { Dynamism: } \\
\left(\mathrm{E}_{\text {DYN }}\right)\end{array}$} & $\begin{array}{c}\text { Zero } \\
\text { (0) }\end{array}$ & $\begin{array}{l}\text { Low } \\
(.01)\end{array}$ & $\begin{array}{c}\text { Medium } \\
(.05)\end{array}$ & $\begin{array}{l}\text { High } \\
\text { (.1) }\end{array}$ & $\begin{array}{c}\text { Zero } \\
(0)\end{array}$ & $\begin{array}{l}\text { Low } \\
(.01)\end{array}$ & $\begin{array}{c}\text { Medium } \\
(.05)\end{array}$ & $\begin{array}{l}\text { High } \\
\text { (.1) }\end{array}$ \\
\hline \multirow{3}{*}{$\begin{array}{l}\text { Mean } \\
\text { Perfor- } \\
\text { mance } \\
\text { over } 150 \\
\text { periods }\end{array}$} & $\begin{array}{l}\text { Zero } \\
\text { IOI (0) } \\
\text { (s.d.) }\end{array}$ & $\begin{array}{c}.5927 \\
(.0118)\end{array}$ & $\begin{array}{c}.5905 \\
(.0126)\end{array}$ & $\begin{array}{c}.5932 \\
(.0139)\end{array}$ & $\begin{array}{l}.5916 \\
(.0122)\end{array}$ & $\begin{array}{c}.6007 \\
(.0100)\end{array}$ & $\begin{array}{c}.6004 \\
(.0100)\end{array}$ & $\begin{array}{c}.5994 \\
(.0105)\end{array}$ & $\begin{array}{l}.5999 \\
(.0095)\end{array}$ \\
\hline & $\begin{array}{l}\text { Medium } \\
\text { IOI (.2) } \\
\text { (s.d.) }\end{array}$ & $\begin{array}{c}.5935 \\
(.0149)\end{array}$ & $\begin{array}{l}.5928 \\
(.0135\end{array}$ & $\begin{array}{l}.5949 \\
(.0141\end{array}$ & $\begin{array}{l}.5935 \\
(.0138\end{array}$ & $\begin{array}{c}.6008 \\
(.0116)\end{array}$ & $\begin{array}{c}.6003 \\
(.0105)\end{array}$ & $\begin{array}{c}.6022 \\
(.0103)\end{array}$ & $\begin{array}{l}.6016 \\
(.0110)\end{array}$ \\
\hline & $\begin{array}{l}\text { High } \\
\text { IOI (.5) } \\
\text { (s.d.) }\end{array}$ & $\begin{array}{c}.5889 \\
(.0128)\end{array}$ & $\begin{array}{l}.5888 \\
(.0139\end{array}$ & $\begin{array}{l}.5942 \\
(.0144\end{array}$ & $\begin{array}{l}.5933 \\
(.0142\end{array}$ & $\begin{array}{c}.5994 \\
(.0122)\end{array}$ & $\begin{array}{c}.5996 \\
(.0121)\end{array}$ & $\begin{array}{c}.6014 \\
(.0112)\end{array}$ & $\begin{array}{c}.6004 \\
(.0106)\end{array}$ \\
\hline \multicolumn{2}{|c|}{$\begin{array}{l}\text { \%-change from } \\
\text { zero to Medium IOI } \\
\text { (p-values) }\end{array}$} & $\begin{array}{l}0.14 \% \\
(.2671)\end{array}$ & $\begin{array}{c}0.39 \% * \\
(.0296)\end{array}$ & $\begin{array}{l}0.27 \% \\
(.1253)\end{array}$ & $\begin{array}{l}0.32 \% \%^{+} \\
(.0657)\end{array}$ & $\begin{array}{l}0.01 \% \\
(.4846)\end{array}$ & $\begin{array}{l}-0.01 \% \\
(.4661)\end{array}$ & $\begin{array}{l}0.47 \% * \\
(.0049)\end{array}$ & $\begin{array}{c}0.28 \% * \\
(.0529)\end{array}$ \\
\hline \multicolumn{2}{|c|}{$\begin{array}{l}\text { \%-change from } \\
\text { zero to High IOI } \\
\text { (p-values) }\end{array}$} & $\begin{array}{c}-.63 \% * * \\
(.0010)\end{array}$ & $\begin{array}{l}-0.28 \% \\
(.1016)\end{array}$ & $\begin{array}{c}0.16 \% \\
(.2446)\end{array}$ & $\begin{array}{l}0.29 \% \%^{+} \\
(.0954)\end{array}$ & $\begin{array}{l}-0.22 \% \\
(.1345)\end{array}$ & $\begin{array}{l}-0.13 \% \\
(.2220)\end{array}$ & $\begin{array}{c}0.35 \% * \\
(.0247)\end{array}$ & $\begin{array}{c}0.08 \% \\
(.3142)\end{array}$ \\
\hline \multicolumn{2}{|c|}{$\begin{array}{l}\text { \%-change from } \\
\text { Medium to High } \\
\text { IOI (p-values) }\end{array}$} & $\begin{array}{c}-0.77 \% * * \\
(.0006)\end{array}$ & $\begin{array}{c}-0.67 \% * * \\
(.0019)\end{array}$ & $\begin{array}{l}-0.11 \% \\
(.3213)\end{array}$ & $\begin{array}{l}-0.03 \% \\
(.4448)\end{array}$ & $\begin{array}{l}-0.23 \% \\
(.1329)\end{array}$ & $\begin{array}{l}-0.12 \% \\
(.2639)\end{array}$ & $\begin{array}{l}-0.12 \% \\
(.2356)\end{array}$ & $\begin{array}{l}-0.20 \% \\
(.1207)\end{array}$ \\
\hline
\end{tabular}


Table 3. Innovation performance across different scenarios in global industries

\begin{tabular}{|c|c|c|c|c|c|c|c|c|c|}
\hline \multirow{2}{*}{\multicolumn{2}{|c|}{$\begin{array}{c}\text { Observations: } 200 \\
\begin{array}{c}\text { Simulations Per } \\
\text { Scenario }\end{array} \\
\text { Complexity: }\end{array}$}} & \multicolumn{8}{|c|}{ Global Industries $\left(\mathrm{X}_{\mathrm{REL}}=\mathbf{0 . 2}\right)$} \\
\hline & & \multicolumn{4}{|c|}{ Low complexity $\left(K_{w}=1\right)$} & \multicolumn{4}{|c|}{ High Complexity $\left(K_{w}=3\right)$} \\
\hline \multicolumn{2}{|c|}{$\begin{array}{r}\text { Dynamism: } \\
\left(\mathrm{E}_{\mathrm{DYN}}\right)\end{array}$} & $\begin{array}{c}\text { Zero } \\
\text { (0) }\end{array}$ & $\begin{array}{l}\text { Low } \\
(.01)\end{array}$ & $\begin{array}{c}\text { Medium } \\
(.05)\end{array}$ & $\begin{array}{l}\text { High } \\
\text { (.1) }\end{array}$ & $\begin{array}{c}\text { Zero } \\
(\mathbf{0})\end{array}$ & $\begin{array}{l}\text { Low } \\
(.01)\end{array}$ & $\begin{array}{c}\text { Medium } \\
(.05)\end{array}$ & $\begin{array}{l}\text { High } \\
(.1)\end{array}$ \\
\hline \multirow{3}{*}{$\begin{array}{l}\text { Mean } \\
\text { Perfor- } \\
\text { mance } \\
\text { over } \\
150 \\
\text { periods }\end{array}$} & $\begin{array}{l}\text { Zero } \\
\text { IOI (0) } \\
\text { (s.d.) }\end{array}$ & $\begin{array}{c}.6437 \\
(.0285)\end{array}$ & $\begin{array}{c}.6459 \\
(.0280)\end{array}$ & $\begin{array}{c}.6428 \\
(.0261)\end{array}$ & $\begin{array}{c}.6470 \\
(.0296)\end{array}$ & $\begin{array}{c}.6463 \\
(.0213)\end{array}$ & $\begin{array}{c}.6463 \\
(.0222)\end{array}$ & $\begin{array}{c}.6470 \\
(.0233)\end{array}$ & $\begin{array}{c}.6459 \\
(.0206)\end{array}$ \\
\hline & $\begin{array}{l}\text { Medium } \\
\text { IOI (.2) } \\
\text { (s.d.) }\end{array}$ & $\begin{array}{c}.6489 \\
(.0298)\end{array}$ & $\begin{array}{c}.6505 \\
(.0301)\end{array}$ & $\begin{array}{c}.6508 \\
(.0284)\end{array}$ & $\begin{array}{c}.6465 \\
(.0315)\end{array}$ & $\begin{array}{c}.6508 \\
(.0219)\end{array}$ & $\begin{array}{c}.6500 \\
(.0224)\end{array}$ & $\begin{array}{c}.6525 \\
(.0230)\end{array}$ & $\begin{array}{c}.6557 \\
(.0237)\end{array}$ \\
\hline & $\begin{array}{l}\text { High } \\
\text { IOI (.5) } \\
\text { (s.d.) }\end{array}$ & $\begin{array}{c}.6481 \\
(.0289)\end{array}$ & $\begin{array}{c}.6454 \\
(.0297)\end{array}$ & $\begin{array}{c}.6514 \\
(.0323)\end{array}$ & $\begin{array}{c}.6509 \\
(.0353)\end{array}$ & $\begin{array}{c}.6474 \\
(.0241)\end{array}$ & $\begin{array}{c}.6517 \\
(.0238)\end{array}$ & $\begin{array}{c}.6521 \\
(.0239)\end{array}$ & $\begin{array}{c}.6512 \\
(.0239)\end{array}$ \\
\hline \multicolumn{2}{|c|}{$\begin{array}{l}\% \text {-change from } \\
\text { zero to Medium IOI } \\
\text { (p-values) }\end{array}$} & $\begin{array}{c}0.80 \% * \\
(.0364)\end{array}$ & $\begin{array}{l}0.71 \% * \\
(.0531)\end{array}$ & $\begin{array}{c}1.25 \% * * \\
(.0019)\end{array}$ & $\begin{array}{l}-0.08 \% \\
(.4349)\end{array}$ & $\begin{array}{c}0.70 \% * \\
(.0234)\end{array}$ & $\begin{array}{c}0.58 \% * \\
(.0493)\end{array}$ & $\begin{array}{c}0.84 \% * * \\
(.0095)\end{array}$ & $\begin{array}{c}1.52 \% * * \\
(.0000)\end{array}$ \\
\hline \multicolumn{2}{|c|}{$\begin{array}{l}\% \text {-change from } \\
\text { zero to High IOI } \\
\text { (p-values) }\end{array}$} & $\begin{array}{l}\mathbf{0 . 6 8 \%} \%^{+} \\
(.0603)\end{array}$ & $\begin{array}{l}-0.07 \% \\
(.4410)\end{array}$ & $\begin{array}{c}1.34 \% * * \\
(.0011)\end{array}$ & $\begin{array}{l}0.60 \% \\
(.1255)\end{array}$ & $\begin{array}{l}0.18 \% \\
(.3041)\end{array}$ & $\begin{array}{c}0.85 \% * * \\
(.0094)\end{array}$ & $\begin{array}{l}0.78 \% * \\
(.0162)\end{array}$ & $\begin{array}{c}0.82 \% * * \\
(.0071)\end{array}$ \\
\hline \multicolumn{2}{|c|}{$\begin{array}{l}\% \text {-change from } \\
\text { Medium to High IOI } \\
\text { (p-values) }\end{array}$} & $\begin{array}{l}-0.13 \% \\
(.3942)\end{array}$ & $\begin{array}{c}-0.77 \% * \\
(.0426)\end{array}$ & $\begin{array}{c}0.08 \% \\
(.4317)\end{array}$ & $\begin{array}{l}0.68 \% \%^{+} \\
(.0953)\end{array}$ & $\begin{array}{c}-0.52 \%{ }^{+} \\
(.0689)\end{array}$ & $\begin{array}{c}0.27 \% \\
(.2065)\end{array}$ & $\begin{array}{l}-0.06 \% \\
(.4348)\end{array}$ & $\begin{array}{c}-0.68 \% * \\
(.0246)\end{array}$ \\
\hline
\end{tabular}

Significance levels: $+0.10 * 0.05 * * 0.01$. Diversification high/unrelated $\left(\mathrm{K}_{\mathrm{b}}=.2\right)$.

Figure 3. Interaction of IOI and dynamism in international low-tech industries

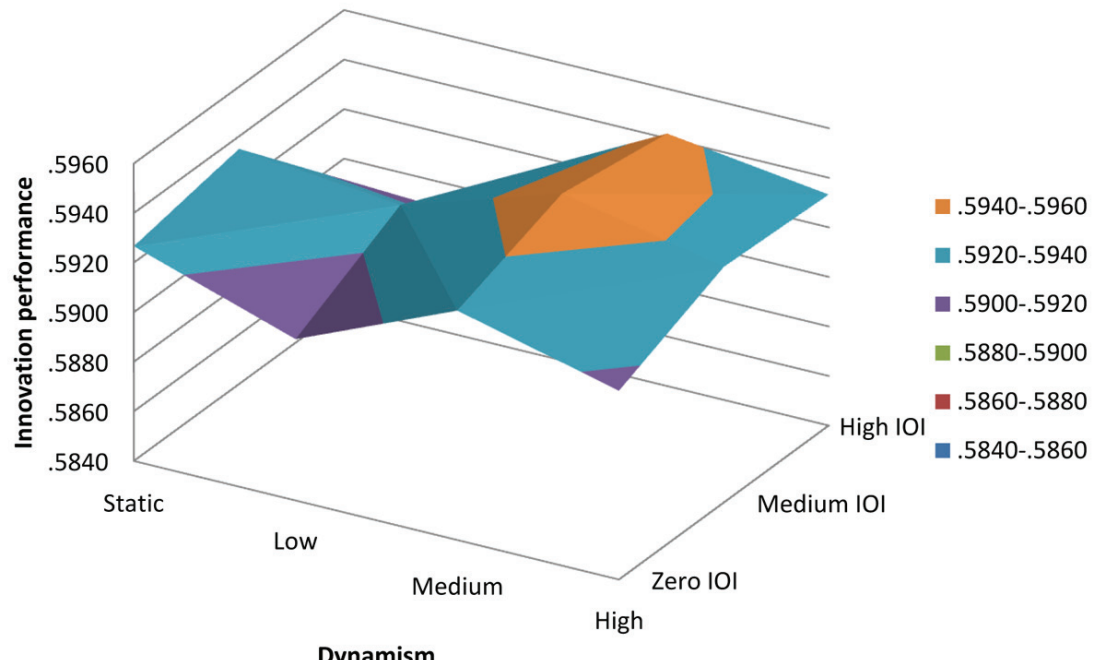


Figure 4. Interaction of IOI and dynamism in international high-tech industries

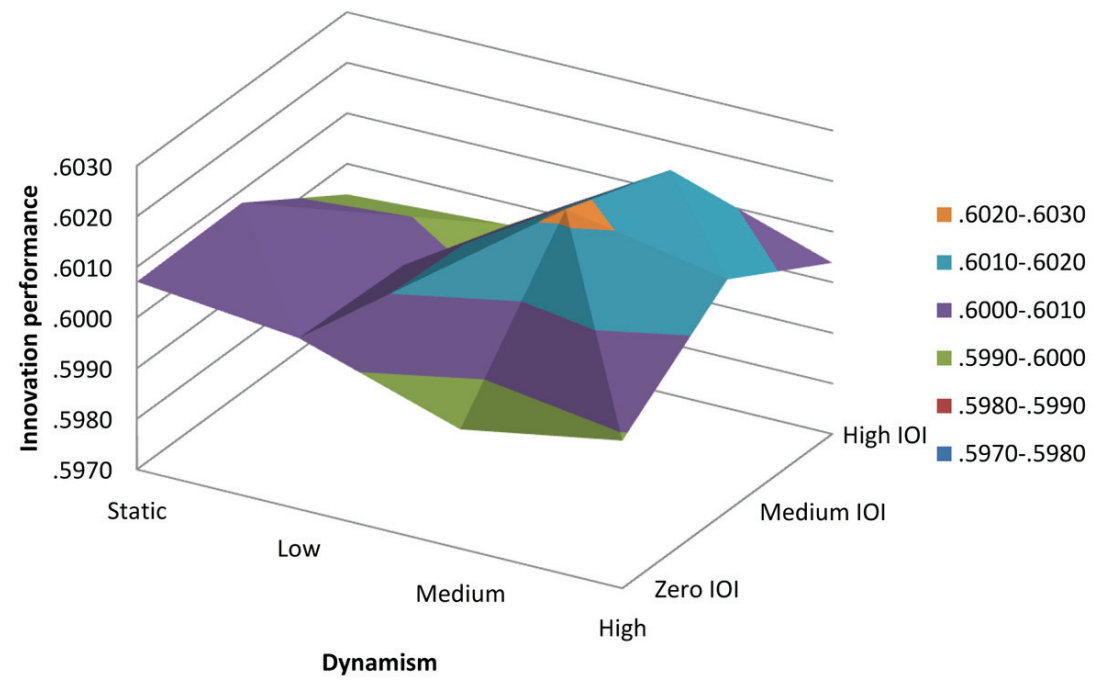

Figure 5. Interaction of IOI and dynamism in global low-tech industries

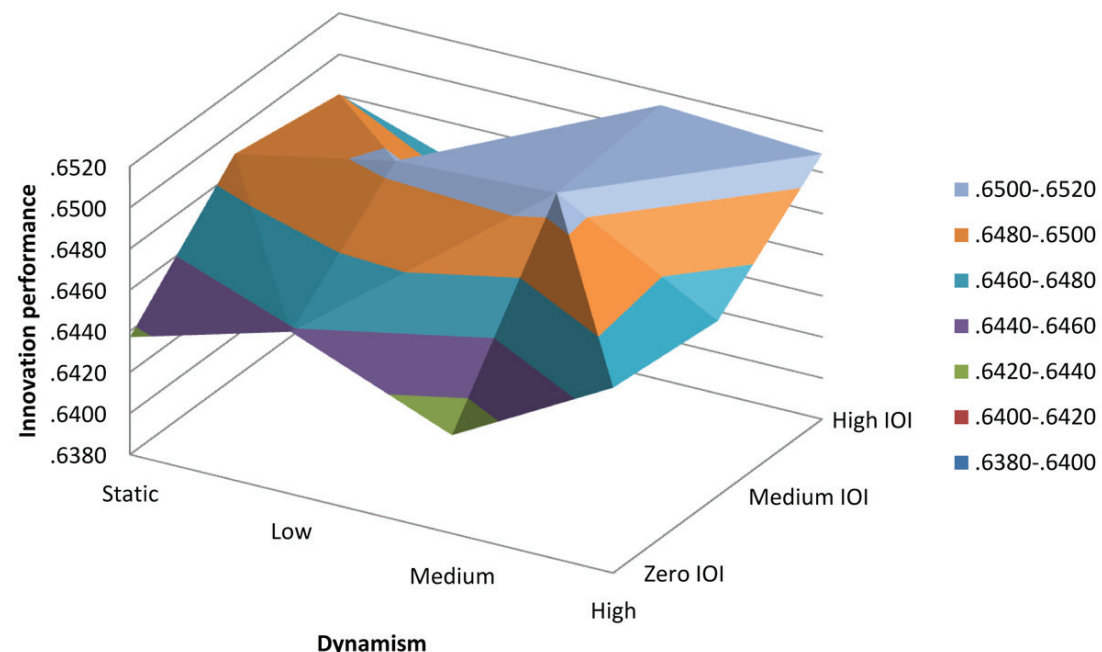

industries local context may differ widely can be deemed one of the principal reasons behind the significant impact of distance on the success of knowledge transfer (Davenport, 2005). This might be caused by interdependences between local context factors on the one hand and particular combinations of operative and strategic decisions on the other. The importance of the local market is also reflected in the significant positive effect that has been found from market orientation on business performance (e.g. Verhoef \& Leeflang, 2009). In other words, it is both the demand-side environment and the working environment, or culture, which can be quite different from country to country. In effect, knowledge developed locally by a 
Figure 6. Interaction of IOI and dynamism in global high-tech industries

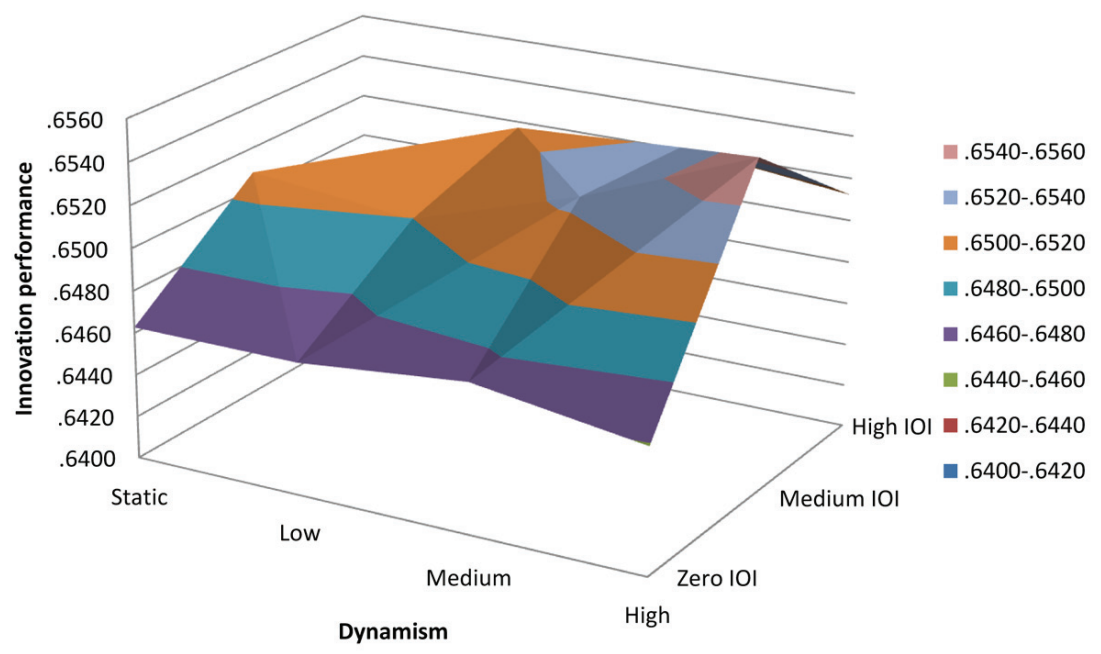

given subsidiary can be less functional for a subsidiary belonging to another country and environmental complexity and turbulence are generally understood as the two major constituencies of (perceived) environmental uncertainty (Duncan, 1972).

A first important finding is that the effect that the environmental dynamism has on the convenience of IOI (see the significance of relative differences between the various levels of IOI) is fundamentally different at various levels of complexity. While in high complexity environments, medium and high dynamism offers opportunities to improve performance through the implementation of IOI in the MNC subsidiary network, in low complexity environments, it is the opposite. However, at zero dynamism, excessive IOI can actually be detrimental to innovation performance. Results are illustrated for more intuitive comparison in Figures 3 and 4.

We find fundamentally different effects in the case of global industries (see Table 3 and Figure 5 and 6). For high complexity environments, we find that the impact of medium levels of IOI on innovation performance increases with environmental dynamism.
For low complexity environments, we find a quite different effect of environmental dynamism on the relationship between IOI and innovation performance. First of all, in low complexity environments, high levels of IOI are convenient only in case of medium dynamism; but then its effect is amongst the highest. Furthermore, in low complexity environments, medium levels of IOI appear to impact innovation performance in an inverse u-shaped manner across increasing levels of environmental dynamism. The highest effect can be observed in both cases at medium levels of environmental dynamism, where however the difference between medium and high level IOI is not significant.

\section{DISCUSSION}

One counter-intuitive result is that IOI might indeed even have a negative impact on innovation performance. This could be explained by a too early homogenization of the subsidiary network. That knowledge heterogeneity has a highly significant, positive influence on innovativeness has been shown also empirically at the example of managers and their ego-networks' content (Rodan \& Galunic, 2004). Subsidiaries 
decide at the first slow down of their own innovation process to gather superior knowledge from a similar peer in order to switch to a currently higher performing innovation path that, however, offers less long-term potential. In the language of NK-landscapes, this means that since the landscape is relatively smooth, valleys of attraction are larger and thus chances are higher that subsidiaries too early switch through IOI to a valley of attraction that leads to a lower local optimum. This happens in those cases where the source subsidiary already reached a higher performing point on its innovation path while the maximal reachable performance of this current path is actually lower.

Proposition 1(a): In international industries exposed to low complexity environments that are completely static, a high level of IOI has, ceteris paribus, a negative impact on innovation performance.

Absolutely static and predictable environments are a mere theoretic extreme. Therefore it is important to note that this negative effect of high levels of IOI is not significant anymore even in only little dynamic environments. Also the effect of medium levels of IOI, in this case, becomes significantly positive. It appears that in international, low complexity environments dynamism plays only a very limited role as long as it is not extremely low for medium levels of IOI. Hence, subsidiary managers can foster their innovation performance if they moderately source knowledge from similar peer subsidiaries. In this way they can acquire the benefits from jumping to a currently higher performing development path while still relying on own development from thereon. This means to balance more exploitative own innovation activities with exploration of more distant knowledge from peer subsidiaries, which is in line with previous suggestions in simulation studies that argue for the necessity of a suchlike balance (e.g. March, 1991). A high frequency of knowledge sourcing by subsidiaries leaves little time to further innovative based on the sourced knowledge. This might explain why this option depends on environmental dynamism. If dynamism is low, exploration is more successful by jumping on a currently well performing innovation because there is little time to improve from there on anyways.

Proposition 1(b): In international industries exposed to low complexity environments, a medium level of IOI has a positive impact on innovation performance independent from whether environment is little, medium of highly dynamic.

Proposition 1(c): In international industries exposed to low complexity environments, environmental dynamism positively impacts the effect of IOI so that the effect from IOI on innovation performance changes the sign from negative at low levels of dynamism to positive at high levels.

In complex environments, IOI even at medium levels depends on dynamism. That is, in complex but static or low dynamic environments, IOI appears to have no impact at all whereas it has a significant positive one at medium and high levels of dynamism. This might be interpreted as an indication for how high-tech companies can gain competitive advantage by fostering IOI amongst their subsidiaries. Since fitness landscapes in complex high-tech industries are more rugged, subsidiaries that apply common incremental exploitative search will tend to finish early on at a local optimum. This might appear to be a valuable competence at this point because the overall structure of the fitness landscape is unknown, but actually might be a rigidity detrimental to long-term performance (Leonard-Barton, 1992). In order to continue innovative activity, new input on other, more explorative innovative combinations of knowledge are needed. However, if there is no dynamism, on average there is little to gain, since in static environments also the other subsidiaries run the same risk to be stuck in inconvenient innovation paths. At higher degrees of dynamism though, chances are higher, that the current innovation path of one subsidiary or another is revalued and offers 
suddenly a higher value potential. In this way, IOI permits subsidiaries to supplement own exploitative search activity with exploration of very different, innovative combinations.

Proposition 2: In international industries that present high complexity environments to the MNCs

Proposition 2(a): At medium and high levels of dynamism, a medium level of IOI throughout the MNC subsidiary network has, ceteris paribus, the most positive impact on innovation performance, while

Proposition 2(b): IOI has, ceteris paribus, no significant impact at zero and low levels of dynamism.

For global industries, the dynamics are intensified, since more subsidiaries exist that offer indeed very similar environments. The great impact of medium level of IOI for a high level of environmental complexity can be interpreted as suggesting that in global industries the subsidiaries have better chances to jump actually to a valley of attraction with a higher local optimum. This corroborates early findings in the literature investigating the phenomenon of R\&D globalization, which show inter alia that a major goal of global R\&D is in fact the access to globally dispersed knowledge sources (Florida, 1997). In global industries, the probability is higher for subsidiaries to actually have a peer in a different country with almost the same key environmental factors. Hence it is also more probable to discover knowledge about a better performing set of innovative knowledge amongst peer subsidiaries. This is even more important in cases where the value of once locally generated knowledge erodes faster and only little time is given to find a well performing new combination of knowledge before the next changes in the environment erode also these insights. Qualitative results of highly dynamic and complex industries suggest that in this case it is very important to explore contemporaneously diverse innovation paths but yet maintain inter-project communication through "semistructures" at moderate levels (Brown \& Eisenhardt, 1997). This is particularly corroborated by our results in form of the significantly higher performance increase through medium vis-à-vis high IOI.

Proposition 3: In global industries, which are exposed to high complexity environments,

Proposition 3(a): The positive effect of medium levels of IOI increases linearly with environmental dynamism, while

Proposition 3(b): High levels of IOI increase innovation performance almost equally from low to high levels of dynamism, exhibiting a significantly lower positive impact than medium IOI only in cases of high dynamism.

An intriguing result is that at very high degrees of environmental dynamism there is no significant effect of IOI at no level. This surprises because intuition could lead to the conclusion that external knowledge is helpful when the own knowledge erodes very fast. However, the observed results might be explained by a similar reasoning as in case of international industries. In low complexity environments, as e.g. low-tech industries, development paths in the own environment are quite foreseeable, i.e. there are few peaks and large valleys of attraction. This makes it less attractive to engage time and resources into knowledge acquisition from outside with the peril to engage on a new development path that might actually lead to a lower local optimum.

Proposition 4: In global industries that are exposed to low complexity environments, Proposition 4(a): IOI has no significant effect at no level in cases of high environmental dynamism, while

Proposition 4(b): A medium level of ioi is moderated by environmental dynamism in its positive impact on innovation performance in an inversely u-shaped manner and 
Proposition 4(c): A high level of IOI impacts positively on innovation performance only in cases of medium environmental dynamism.

\section{CONCLUSION}

In this study we focused on the concept of openness in the innovation process within MNCs' subsidiary networks. We believe that the opening of subsidiaries' innovation process towards their peers within the MNC network might not be positive per se, but highly contingent on the environment. Looking at the $\mathrm{MNC}$ as a network in which different levels of openness can be implemented we highlight how MNC subsidiaries in more or less common problem contexts depend in their joint innovation effort crucially on the interplay between two major environmental characteristics.

We contribute to research in two fundamental ways. Firstly, we develop the notion of Internal Open Innovation of MNCs. Secondly, we develop a model that integrates central contingencies of the innovation impact of Internal Open Innovation of MNCs. This helps to develop an intuition how these factors could interact on the outcomes of MNCs' more or less open innovation strategies. Based on very common and intuitive assumptions and a simple agentbased model, we establish several propositions, while the simulation approach permits us to disentangle the effects in focus independently from other issues. This is crucial because if in an empirical study the effect of intra-MNC knowledge integration is not per se positive this might have several other reasons like e.g. erroneous beliefs ("false knowledge") on the part of the knowledge providers or inadequate absorptive capacity on the part of the knowledge receivers. Herein, we can show that even if everything else is perfect, intra-firm knowledge integration might not have per se a linearly positive effect on innovation performance.

We find that in case of MNC subsidiary networks sensitive to the differences across subsidiaries' problem contexts, i.e. international industries as opposed to global industries with a single worldwide equal context medium to high degrees of dynamism in the MNC's environment should encourage the implementation of internal open innovation strategies in high complexity industries. Moreover, IOI can proof beneficial, ceteris paribus, in low but not too low dynamic environments in case of low complexity industries.

We further find that this relation is ambiguous when dynamism is at a medium level. Although environmental complexity already alters significantly the degree of the positive and negative relation in low and high dynamic environments, in cases of medium dynamic environments, complexity is a strong moderator changing even the nature of the relationship from positive to negative. In particular, we find support that in these cases of medium dynamism, MNCs can profit from medium levels of internal open innovation if complexity is low, while there is no such effect in cases of high complexity. On the contrary, high levels of internal open innovation will result in worse innovation performance.

Finally, it can be claimed that this research could also have managerial implications once empirically underpinned. If companies are unsure in what category their environment falls, a moderate level of IOI can hardly harm innovation performance whereas in many cases it actually might foster it. The intuition is that in stable environments subsidiaries that exchange knowledge during the innovation process can explore different strands of research and adopt the one that yields better results early on and these results remain valid. In instable contexts a highly profitable innovation might be adopted from heterogeneous subsidiaries, but does not remain valid for long and from the point on that the environment changes both restart their search from the homogenized knowledge, which exhibits less potential solutions than searching with different knowledge backgrounds. This can have a long term negative effect.

Generally, we argue that the analysis of subsidiaries' varying degrees of openness and the contingencies that moderate its impact on innovation performance can contribute to 
a better understanding of how MNCs should incentivize their subsidiaries to collaborate in the innovation process. However, the costs - in terms of loss of diversity of knowledge bases and allocation of resources to IOI instead of independent innovative activities - have to be considered when pursuing its benefits - in terms of higher yield knowledge, faster adaption to changing and wider exploration of complex environments.

However, in this model we assume that managers can perfectly understand and foresee whether their problem context is similar to that of peer subsidiaries or not. This assumption could be relaxed in future studies elaborating the herein developed model. Moreover, it seems promising to investigate whether there is a potential trade-off between internal innovation collaboration, i.e. with peer subsidiaries, and external innovation collaboration, i.e. with local sources from which arrive knowledge spillovers and if so of what nature. For both cases our simulation model provides a sound fundament to theorize these potentially complex relationships.

Moreover, a further limitation can be seen in the fact that some studies have shown that cultural differences can lead to problems when systems built to share knowledge are deployed outside the original cultural context, as e.g. the group of Western countries (Ardichvili, Maurer, \& Li, 2006; Marzo, Za, \& Spagnoletti, 2013; Voelpel \& Han, 2005; M.-L. Young, Kuo, \& Myers, 2012). Since a knowledge management system can reflect the Western values of the designers (Nonaka \& Takeuchi, 1995), such cultural issues can be important in the consideration of planning and managing knowledge sharing. In fact, since such cultural differences could influence the success of knowledge transfer between subsidiaries and therewith also that of IOI beyond the issue of disseminative and absorptive capacities of the involved units, it would be an interesting supplement to our model that could be addressed in future studies to investigate how the thus assumed differences in communication approaches might alter our findings.

\section{ACKNOWLEDGMENT}

This paper is part of the doctoral dissertation of the first author at LUISS Guido Carli. The authors gratefully acknowledge most helpful comments by Professor Peter S. H. Leeflang, the editor of IJESMA, Professor Alberto Francesconi, as well as three anonymous reviewers. All remaining errors are ours.

\section{REFERENCES}

Albino, V., Garavelli, C., \& Schiuma, G. (1998). Knowledge transfer and inter-firm relationships in industrial districts: The role of the leader firm. Technovation, 19(1), 53-63. doi:10.1016/S01664972(98)00078-9

Almeida, P., \& Phene, A. (2004). Subsidiaries and knowledge creation: The influence of the MNC and host country on innovation. Strategic Management Journal, 25(89), 847-864. doi:10.1002/smj.388

Ardichvili, A., Maurer, M., \& Li, W. (2006). Cultural influences on knowledge sharing through online communities of practice. Journal of Knowledge Management, 10(1), 94-107. doi:10.1108/13673270610650139

Argote, L., \& Ingram, P. (2000). Knowledge transfer: A basis for competitive advantage in firms* 1 . Organizational Behavior and Human Decision Processes, 82(1), 150-169. doi:10.1006/obhd.2000.2893

Bartlett, C. A., \& Ghoshal, S. (1990). The multinational corporation as an interorganizational network. Academy of Management Review, 15(4), 603-625.

Benito, G. R. G., Lunnan, R., \& Tomassen, S. (2010). Distant encounters of the third kind: Multinational companies locating divisional headquarters abroad. Journal of Management Studies. doi:10.1111/j.14676486.2010.00962.x

Birkinshaw, J., \& Hood, N. (1998). Multinational subsidiary evolution: Capability and charter change in foreign-owned subsidiary companies. Academy of Management Review, 23(4), 773-796.

Bourdieu, P. (1986). The forms of capital. In W. B. Nicole (Ed.), Readings in economic sociology (pp. 280-291). Oxford, UK: Blackwell Publisher Ltd. 
Brown, J. S., \& Duguid, P. (1991). Organizational learning and communities-of-practice: Toward a unified view of working, learning, and innovation. Organization Science, 2(1), 40-58. doi:10.1287/ orsc. 2.1 .40

Brown, S. L., \& Eisenhardt, K. M. (1997). The art of continuous change: Linking complexity theory and time-paced evolution in relentlessly shifting organizations. Administrative Science Quarterly, 42(1), 1-34. doi:10.2307/2393807

Chang, S.-J., \& Park, S. (2005). Types of firms generating network externalities and MNCs' co-location decisions. Strategic Management Journal, 26(7), 595-615. doi:10.1002/smj.464

Charalabidis, Y., Lampathaki, F., \& Askounis, D. (2010). Investigating the landscape in national interoperability frameworks. International Journal of E-Services and Mobile Applications, 2(4), 28-41. doi:10.4018/jesma.2010100103

Chesbrough, H. W. (2003a). Open innovation: The new imperative for creating and profiting from technology: 227. Boston, MA: Harvard Business School Press.

Chesbrough, H. W. (2003b). The era of open innovation. MIT Sloan Management Review, 35-42.

Chesbrough, H. W. (2004). Managing open innovation. Research Technology Management, 47(1), 23-26.

Davenport, S. (2005). Exploring the role of proximity in SME knowledge-acquisition. Research Policy, 34(5), 683-701. doi:10.1016/j.respol.2005.03.006

Doukas, J. A., \& Kan, O. B. (2006). Does global diversification destroy firm value? Journal of International Business Studies, 37(3), 352-371. doi:10.1057/palgrave.jibs. 8400203

Doz, Y. L., \& Prahalad, C. K. (1991). Managing DMNCs: A search for a new paradigm. Strategic Management Journal, 12, 145-164. doi:10.1002/ smj.4250120911

Duncan, R. B. (1972). Characteristics of organizational environments and perceived environmental uncertainty. Administrative Science Quarterly, ".", 313-327. doi:10.2307/2392145

Dunning, J. (1981). International production and the multinational enterprise: 439. London, UK: Allen \& Unwin.
Eisenhardt, K. M., \& Tabrizi, B. N. (1995). Accelerating adaptive processes: Product innovation in the global computer industry. Administrative Science Quarterly, 40(1), 84. doi:10.2307/2393701

Florida, R.(1997). The globalization of R\&D: Results of a survey of foreign-affiliated R\&D laboratories in the USA. Research Policy, 26, 85-103. doi:10.1016/ S0048-7333(97)00004-8

Foss, N. J., \& Pedersen, T. (2004). Organizing knowledge processes in the multinational corporation: An introduction. Journal of International Business Studies, 35(5), 340-349. doi:10.1057/palgrave. jibs. 8400102

Gassmann, O., \& Enkel, E. (2004). Towards a theory ofopen innovation: Three core process archetypes. In Proceedings of the R\&D Management Conference, Lisbon, Portugal (p. 18).

Gavetti, G., \& Levinthal, D. A. (2000). Looking forward and looking backward: Cognitive and experiential search. Administrative Science Quarterly, 45(1), 113. doi:10.2307/2666981

Gavetti, G., Levinthal, D. A., \& Rivkin, J. W. (2005). Strategy making in novel and complex worlds: The power of analogy. Strategic Management Journal, 26(8), 691-712. doi:10.1002/smj.475

Ghoshal, S., \& Nohria, N. (1993). Horses for courses: Organizational forms for multinational corporations. Sloan Management Review, 34(2), 23-35.

Goold, M., Pettifer, D., \& Young, D. (2001). Redesigning the corporate centre. European Management Journal, 19(1), 83-91. doi:10.1016/S02632373(00)00073-6

Gupta,A. K., \& Govindarajan, V.(2000). Knowledge flows within multinational corporations. Strategic Management Journal,21(4), 473-496. doi:10.1002/ (SICI)1097-0266(200004)21:4<473::AIDSMJ84>3.0.CO;2-I

Habib, M. M., \& Victor, B. (1991). Strategy, structure, and performance of U.S. manufacturing and service MNCs: A comparative analysis. Strategic Management Journal, 12(October), 589-606. doi:10.1002/ smj.4250120803

Hamel, G. (1991). Competition for competence and interpartner learning within international strategic alliances. Strategic Management Journal, 12(1), 83-103. doi:10.1002/smj.4250120908 
Hansen, M. T. (1999). The search-transfer problem: The role of weak ties in sharing knowledge across organization subunits. Administrative Science Quarterly, 44(1), 82-111. doi:10.2307/2667032

Hendlund, G. (1986). The hypermodern MNC - A heterarchy? Human Resource Management.

Jerez-Gómez, P., Céspedes-Lorente, J., \& ValleCabrera, R. (2005). Organizational learning capability: A proposal of measurement. Journal of Business Research, 58(6), 715-725. doi:10.1016/j. jbusres.2003.11.002

Katz, R., \& Allen, T. J. (1982). Investigating the not invented here (NIH) svndrome: A look at the performance, tenure, and communication patterns of 50 R\&D Project Groups. $R \&$ D Management, 12 (1), 7-19. doi:10.1111/j.1467-9310.1982.tb00478.x

Kauffman, S. (1993). The origins of order: Self-organization and selection in evolution. Oxford, UK: Oxford University Press.

Kogut, B., \& Zander, U. (1992). Knowledge of the firm, combinative capabilities, and the replication of technology. Organization Science, 3(3), 383-397. doi:10.1287/orsc.3.3.383

Kogut, B., \& Zander, U. (1993). Knowledge of the firm and the evolutionary theory of the multinational corporation. Journal of International Business Studies, 24(4), 625-645. doi:10.1057/palgrave. jibs. 8490248

Kuemmerle, W. (1997). Building effective R\&D capabilities abroad. Harvard Business Review, (March-April): 61-70. PMID:10165450

Leonard-Barton, D. (1992). Core capabilities and core rigidities: A paradox in managing new product development. Strategic Management Journal, 13, 111-125. doi:10.1002/smj.4250131009

Levinthal, D. A. (1997). Adaptation on rugged landscapes. Management Science, 43(7), 934-950. doi: $10.1287 / \mathrm{mnsc} .43 .7 .934$

March, J. G. (1991). Exploration and exploitation in organizational learning. Organization Science, 2(1), 71-87. doi:10.1287/orsc.2.1.71

Marengo, L., \& Dosi, G. (2005). Division of labor, organizational coordination and market mechanisms in collective problem-solving. Journal of Economic Behavior \& Organization, 58(2), 303-326. doi:10.1016/j.jebo.2004.03.020
Marzo, F., Za, S., \& Spagnoletti, P. (2013). Modeling dependence networks for agent based simulation of online and offline communities. In Y. Demazeau, T. Ishida, J. M. Corchado Rodríguez, \& J. Bajo Pérez (Eds.), Lecture notes in artificial intelligence (LNAI vol. ): 330. Heidelberg: Springer.

McGill, M. E., Slocum, J. W., \& Lei, D. (1992). Management practices in learning organizations. Organizational Dynamics, 21(1), 5-17. doi:10.1016/00902616(92)90082-X

Mudambi, R., \& Navarra, P. (2004). Is knowledge power? Knowledge flows, subsidiary power and rent-seeking within MNCs. Journal of International Business Studies, 35(5), 385-406. doi:10.1057/palgrave.jibs. 8400093

Nonaka, I., \& Takeuchi, H. (1995). The knowledgecreating company. Oxford University Press.

Rivkin, J. W., \& Siggelkow, N. (2003). Balancing search and stability: Interdependencies among elements of organizational design. Management Science, 49(3), 290-311. doi:10.1287/mnsc.49.3.290.12740

Rodan, S., \& Galunic, C. (2004). More than network structure: How knowledge heterogeneity influences managerial performance and innovativeness. Strategic Management Journal, 25(6), 541-562. http://doi. wiley.com/10.1002/smj.398, November 15, 2012.

Sakhartov,A. V., \& Folta, T. B. (2012). Rationalizing organizational change: A need for comparative testing. Organization Science, 1-17.

Scott, S., \& Bruce, R. (1994). Determinants of innovative behavior: A path model of individual innovation in the workplace. Academy of Management Journal, 37(3), 580-607. doi:10.2307/256701

Siggelkow, N., \& Rivkin, J. W. (2005). Speed and search: Designing organizations for turbulence and complexity. Organization Science, 16(2), 101-122. http://orgsci.journal.informs.org/cgi/doi/10.1287/ orsc.1050.0116, March 19, 2012.

Szulanski, G. (1996). Exploring internal stickiness: Impediments to the transfer of best practice within the firm. Strategic Management Journal, 17(Special Issue (Winter): Knowledge and the Firm): 27-43.

Szulanski, G. (2000). The process of knowledge transfer: A diachronic analysis of stickiness. Organizational Behavior and Human Decision Processes, 82(1), 9-27. doi:10.1006/obhd.2000.2884

Verhoef, P. C., \& Leeflang, P. S. H. (2009). Understanding the marketing department's influence within the firm. Journal of Marketing, 73(March), 1-42. 
Voelpel, S., \& Han, Z. (2005). Managing knowledge sharing in China: The case of Siemens ShareNet. Journal of Knowledge Management, 9(3), 51-63. doi:10.1108/13673270510602764

Walsh, J. P., \& Ungson, G. R. (1991). Organizational memory. Academy of Management Review, 16(1), 57-91.

Wathne, K., Roos, J., \& Von Krogh, G. (1996). Towards a theory of knowledge transfer in a cooprative context. In G. von Krogh, \& J. Roos (Eds.), Managing knowledge: Perspectives on cooperation and competition (pp. 55-81). London, UK: Sage Publication.

Wolfe, R. A. (1994). Organizational innovation: Review, critique and suggested research directions*. Journal of Management Studies, 31(3), 405-431. doi:10.1111/j.1467-6486.1994.tb00624.x

Young, M.-L., Kuo, F.-Y., \& Myers, M. D. (2012). To share or not to share: a critical research perspective on knowledge management systems. European Journal of Information Systems, 21(5), 496-511. doi:10.1057/ejis.2012.10

Za, S., \& Spagnoletti, P. (2013). Knowledge creation processes in Information Systems and Management: Lessons from simulation studies. In P. Spagnoletti (Ed.), Organization change and information systems (LNISO vol.). Heidelberg: Springer. doi:10.1007/9783-642-37228-5 19

Zedtwitz, M., \& Gassmann, O. (2002). Market versus technology drive in $R \& D$ internationalization: four different patterns of managing research and development. Research Policy.

\section{ENDNOTES}

In the following, we refer to IOI when we intend the parameter of individual MNC subsidiaries and to knowledge integration when referring to this parameter on the $\mathrm{MNC}$ level relating it to overall $\mathrm{MNC}$ performance.

This does not mean that the influence of absorptive capacity was not important or should be disregarded, to the contrary. In fact it has found already a lot of consideration in the context of intra-organizational knowledge transfer (cf. van Wijk et al., 2008). However, it was left out for parsimony, but this model could easily be modified to investigate this issue in a future study.

Herein, we do not model the role of HQs for the impact of Internal Open Innovation strategies of its subsidiaries. However, to include the role of HQs as a knowledge broker as well as studying the impact of hierarchy in general and vertical knowledge flows would be interesting extensions of the proposed model.

It could be argued that 0 was a more appropriate value for environmental relevance $\left(X_{R E L}\right)$ in order to simulate global industries, but in reality even the most global industries exhibit some minimum differences in how to do business in different country markets. However, the authors offer to perform further runs with any other combination of parameter values on request as far as resources permit.

\footnotetext{
J. Piet Hausberg studied Business and Economics at Saarland University, the École Supérieure de Gestion, Paris, and the University of Wuppertal. During his studies he worked both as teaching and research assistant, e.g. at the Wuppertal Institute for Climate, Environment and Energy. He received a 3-year scholarship to conduct his PhD in Management at LUISS Guido Carli University Rome. At the moment he is post-doc fellow at the chair for business administration, particularly digital markets, at the School of Business and Social Sciences of the University of Hamburg. His primary research interests are Absorptive Capacity and Open Innovation.
} 
Alfredo Valentino studied Management and Organization both at Federico II University in Naples and at Luiss Guido Carli University in Rome. Currently he is about to conclude his PhD in Management at Luiss Guido Carli University for which he was granted a 3-year scholarship. He worked as teaching assistant in International Management at Luiss Guido Carli. His primary research interests focus on International Business and in particular on the HQ-system design, $H Q$-subsidiaries relations and HQ location decision.

Luca Sabini is a PhD student in management, has studied his Bc at LUISS, and his MSc at Bocconi University in Management of Information System. His thesis was a case study of IT governance in financial Institutions. He has one year of working experience as IT full time consultant for Ernst \& Young and then he is continuing the experience as external specialist contractor. His research interests are related with business organization, Information Technology. 


\section{APPENDIX}

Figure 7. Flowchart of simulated process of IOI

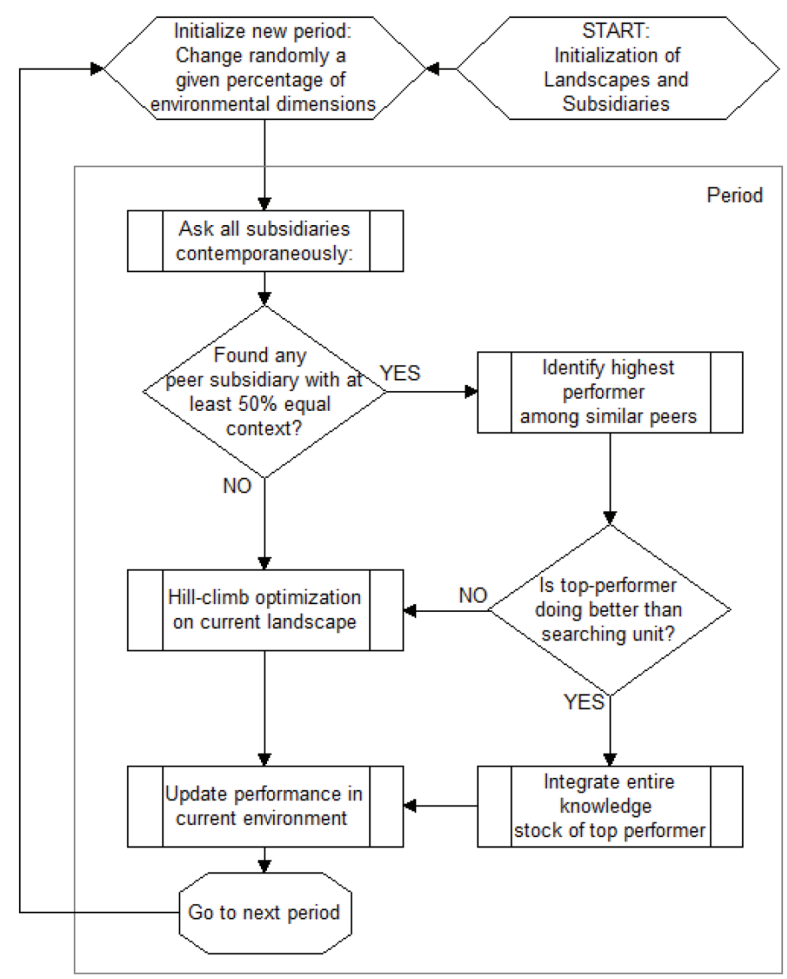

Figure 8. Example of development of MNC innovation performance in complex, high-dynamic, international Industries (smoothed over 200 runs)

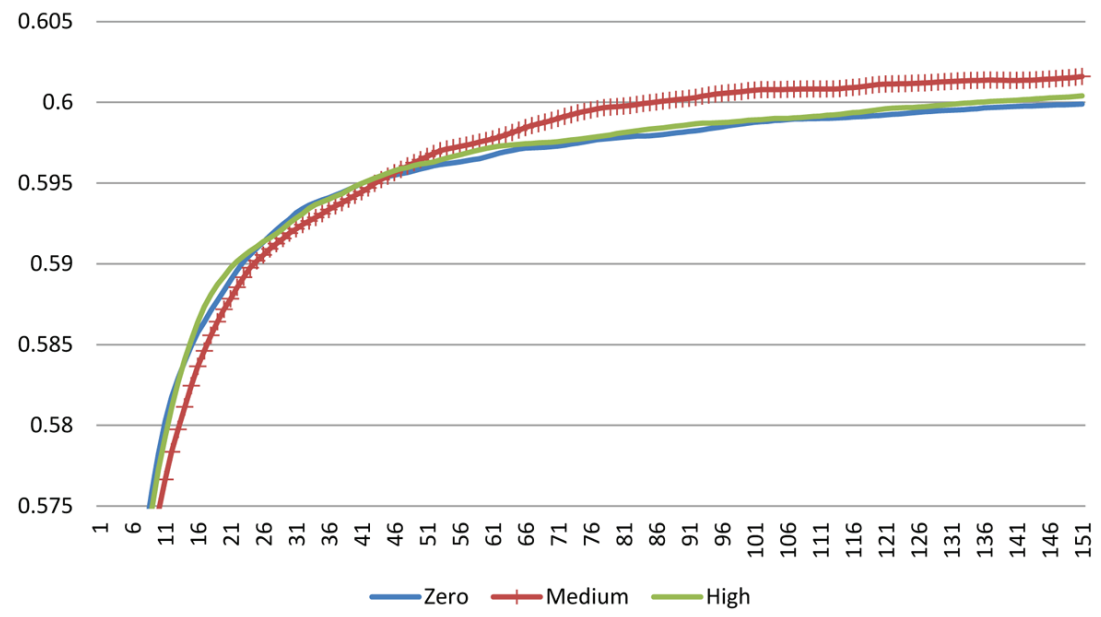




\section{GALL FOR ARTICLES}

\section{International Journal of E-Services and Mobile Applications}

An official publication of the Information Resources Management Association

\section{MISSION:}

The International Journal of E-Services and Mobile Applications (IJESMA) promotes and publishes state-of-the art research regarding different issues in the production management, delivery and consumption of e-services, self services, and mobile communication including business-to-business, business-to-consumer, government-to-business, government-to-consumer, and consumer-to-consumer e-services relevant to the interest of professionals, academic educators, researchers, and industry consultants in the field.

\section{COVERAGE/MAJOR TOPICS:}

- Adoption and diffusion of e-services

- Business models for mobile services

- Conceptual foundations and theoretical frameworks of e-services

- Differences between services and e-services

- E-banking

- E-government

- E-health

- E-learning

- E-libraries

- E-retailing

- E-services and business models

- E-services and competences

- E-services and entrepreneurship

- E-servicesandhumanresourcemanagement

- E-services and innovation

- E-services and knowledge management

- $\quad$ E-services and SMEs

- E-services and strategies
- E-services in the building industry

- E-services in the financial industry

- $\quad$ E-services in vir-

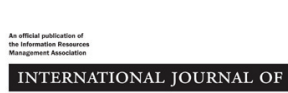

E-Services and Mobile Applications

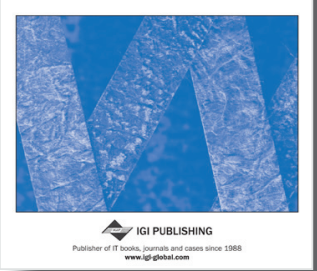

ISSN 1941-627X

eISSN1941-6288

Published quarterly tual worlds

- Internet-based companies providing e-services

- Issues related to e-services, self service, and mobile applications

- $\quad$ IT enabled self-services

- Mobile applications

- Mobile services

- Service science

- Telemedicine

- Transition from industrial to service and e-service economy

- Web-based portals offering different kind of services

All submissions should be mailed to:

Ada Scupola Editor-in-Chief IJESMA

ada@ruc.dk

Ideas for Special Theme Issues may be submitted to the Editor-in-Chief.

Please recommend this publication to your librarian. For a convenient easy-to-use lihrary recommendation form, please visit: http://www.igi-global.com/IJESMA 